\title{
Relative importance of climate factors and human activities in impacting vegetation dynamics during 2000-2015 in the Otindag Sandy Land, northern China
}

\author{
MA Wenyong ${ }^{1,2}$, WANG Xunming ${ }^{1,2^{*}}$, ZHOU Na $^{1,3}$, JIAO Linlin ${ }^{1,2}$ \\ ${ }^{1}$ Key Laboratory of Water Cycle \& Related Land Surface Processes, Institute of Geographic Sciences and Natural Resources \\ Research, Chinese Academy of Sciences, Beijing 100101, China; \\ ${ }^{2}$ University of Chinese Academy of Sciences, Beijing 100049, China; \\ ${ }^{3}$ College of Management Science and Engineering, Hebei University of Economics and Business, Shijiazhuang 050061, China
}

\begin{abstract}
In recent years, there has been increasing research interests in differentiating the relative importance of climate factors and human activities in impacting vegetation dynamics. In this study, based on residual trend method, we used MOD13A3 (MODIS vegetation index product), MCD12Q1 (MODIS land cover product) and meteorological datasets to differentiate the relative importance of climate factors and human activities in impacting vegetation dynamics during 2000-2015 in the Otindag Sandy Land, northern China. Results show that during the study period (2000-2015), the overall vegetation condition had improved in the Otindag Sandy Land. The driving forces of vegetation dynamics differed spatially in the whole study area over the study period. The area with vegetation degradation solely resulted from human activities accounted for $8.23 \%$ of the study area, while the area with vegetation degradation resulted from others (including climate factors and combination of climate factors and human activities) occupied $1.53 \%$. The area with vegetation recovery benefitted from human activities occurred over $26.02 \%$ of the study area; the area benefitted from climate factors accounted for $23.69 \%$; and the area benefitted from both climate factors and human activities occupied $37.74 \%$. All in all, impacts of climate factors and human activities on vegetation dynamics varied at the county/city/banner scales and locality-specific measures should be adopted to protect the environments.
\end{abstract}

Keywords: vegetation; NDVI; climate factors; human factors; Otindag Sandy Land

Citation: MA Wenyong, WANG Xunming, ZHOU Na, JIAO Linlin. 2017. Relative importance of climate factors and human activities in impacting vegetation dynamics during 2000-2015 in the Otindag Sandy Land, northern China. Journal of Arid Land, 9(4): 558-567. doi: 10.1007/s40333-017-0062-y

\section{Introduction}

In arid and semi-arid regions, vegetation degradation threatens the socioeconomic development, while vegetation recovery enhances the development (Mirzabaev et al., 2016). The driving forces of vegetation dynamics are determined by climate factors and human activities (Wang et al., 2012; Xue et al., 2013; Zhou et al., 2015). Some reports have indicated that human activities may be the primary driving force for vegetation dynamics in arid and semi-arid regions (Zheng et al., 2006; Liu and Wang, 2007). However, others have argued that climate factors may be equally or more 
important in driving the vegetation dynamics (Wang et al., 2006; Yang et al., 2007; Liu et al., 2016). All in all, no consensus has yet been reached regarding the relative importance of climate factors and human activities in impacting vegetation dynamics (degradation and recovery) in arid and semi-arid regions. Furthermore, these previous studies mainly focused on qualitatively assessing the main drivers using simple correlation analyses and rather few studies focused on quantitative assessment. In the context of the undergoing global climate change, quantitatively differentiating the relative importance of climate factors and human activities in impacting vegetation dynamics is essential to sustainability in arid and semi-arid regions (Xu et al., 2011).

An appropriate assessment method is a prerequisite for accurately differentiating the relative importance of climate factors and human activities in impacting vegetation dynamics. The commonly-used methods include the residual trend (RESTREND) method, rain use efficiency method, and process-based modelling approach, etc. (Evans and Geerken, 2004; Wessels et al., 2007; Seaquist et al., 2008; Fensholt and Rasmussen, 2011). RESTREND method, based on the residuals of the regression between the vegetation dynamics and influencing factors, has been proved to be suitable to the arid and semi-arid regions of northern China (Xu et al., 2009; Li et al., 2012; He et al., 2015). It should be noted that the normalized difference vegetation index (NDVI) and land cover were usually considered as the indicators of vegetation dynamics (Zhang et al., 2008; Eckert et al., 2015).

The Otindag Sandy Land is located in the agriculture-pasture transition zone in northern China. It has been subjected to varying degrees of degradation in recent decades, leading to intensified desertification (Zhu, 1991; Yang et al., 2005; Liu et al., 2008). The impact of climate change on vegetation dynamics in this region has become increasing important since the early 2000s (Qin, 2014). At the same time, human activities (including population growth, economic expansion, and a series of ecological restoration policies and measures) have exerted equal or greater impacts on vegetation dynamics (Wang et al., 2013; Miao et al., 2015). Thus, it is necessary to quantitatively assess the relative importance of climate factors and human activities in impacting vegetation dynamics since 2000. The objectives of this study were (1) to quantify the spatial-temporal vegetation dynamics in the Otindag Sandy Land; and (2) to identify the relative importance of climate factors and human activities in impacting vegetation dynamics using the RESTREND method. We hope that this study can provide the needed scientific references for sustainable development in this region and other similar regions.

\section{Materials and methods}

\subsection{Study area}

The Otindag Sandy Land is located in the middle of Xilin Gol League, Inner Mongolia Autonomous Region, northern China (Fig. 1). Controlled by the East Asia monsoon system, the study areas is characterized by a continental semi-arid temperate climate with annual mean temperature of $\sim 2^{\circ} \mathrm{C}$ and mean annual precipitation varying from $\sim 400 \mathrm{~mm}$ in the southeast to $\sim 100 \mathrm{~mm}$ in the northwest. Natural vegetation types mainly include desert steppe, steppe, meadow steppe and forest, with vegetation coverage ranging from $<10 \%$ to $\sim 30 \%$. Specifically, desert steppe (with vegetation coverage of $<10 \%$ ) occupies the western region, steppe (with moderate vegetation coverage of $10 \%-20 \%$ ) is dominant in the central region, and meadow steppe and forest (with high vegetation coverage of 20\%-30\%) mainly cover the eastern region. Furthermore, croplands concentrate in the southern and eastern regions. There are a total of 952 plant species belonging to 75 families and 348 genera. The representative perennial herbs are Leymus chinensis, Leymus secalinus, Stipa grandis, Stipa baicalensis, Stipa krylovii, Agropyron cristatum, Agropyron mongolicum, Koeleria cristata and Psammochloa villos, the representative shrubs are Caragana microphylla and Artemisia sp., and the representative tree is Ulmus pumila.

\subsection{Data collection}

2.2.1 Remote sensing datasets

The MODIS MOD13A3 dataset (collection 5; $1000 \mathrm{~m} \times 1000 \mathrm{~m}$ spatial resolution) from February 


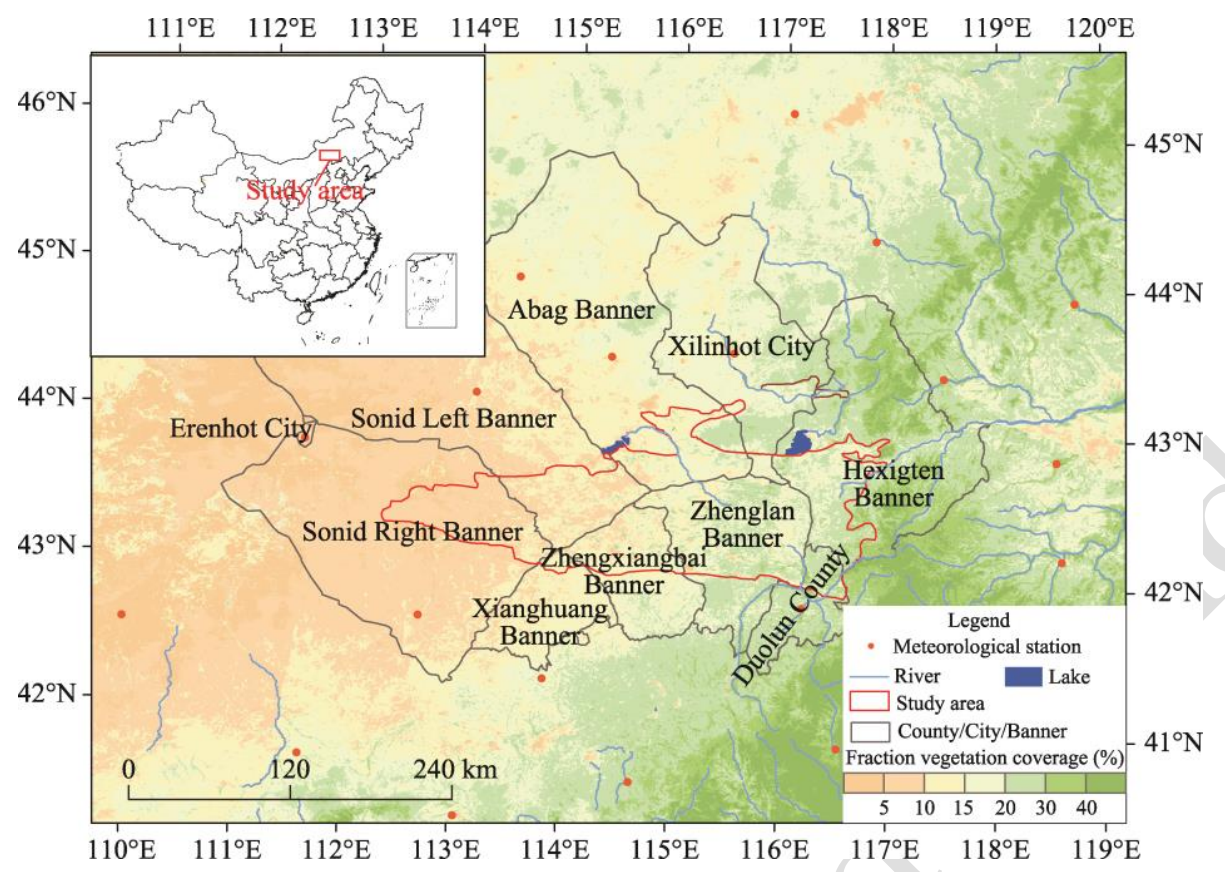

Fig. 1 Location of the study area

2000 to December 2015 was obtained from the USGS Land Processes Distributed Active Archive Center (http://ladsweb.nascom.nasa.gov/data/search.html). As a gridded level-3 product in the sinusoidal projection, the MOD13A3 is a monthly composite of an atmospherically corrected and nadir-adjusted dataset that contains information on the overall usefulness, pixel reliability, and cloud conditions on a per-pixel basis. NDVI was extracted from the MOD13A3 dataset and converted to the Albers equal-area conic projection using MRT software (ftp://e4ftl01u.ecs.nasa.gov/MOLT/).

The MODIS MCD12Q1 dataset (collection 5.1; $500 \mathrm{~m} \times 500 \mathrm{~m}$ spatial resolution) from 2001 to 2013 was obtained from the USGS Land Processes Distributed Active Archive Center (http://ladsweb.nascom.nasa.gov/data/search.html). The MCD12Q1 contains five global land-cover classification systems, including the International Geosphere Biosphere Programme scheme, the University of Maryland scheme, the MODIS-derived LAI/fPAR scheme, the MODIS-derived Net Primary Production scheme and the Plant Functional Type scheme. Based on vegetation characteristics in the study area, we identified grasslands and barren lands (including barren lands and sparsely vegetated lands) as two main land-cover types for the detection of land-cover changes. Specifically, during the period 2001-2013, grasslands occupied $97.47 \%$ of the total study area, barren lands (including barren lands and sparsely vegetated lands) accounted for $1.64 \%$, and others totally occupied $0.89 \%$. The University of Maryland scheme was extracted from the MCD12Q1 product and the classification systems were aggregated into a new classification system comprising three land-cover classes: grasslands, barren lands (including barren lands and sparsely vegetated lands) and others (including croplands, shrublands, forests, water bodies and urban areas).

\subsubsection{Meteorological data}

Meteorological data (including monthly average temperature and monthly precipitation) of 20 meteorological stations within or near the Xilin Gol League, Inner Mongolia Autonomous Region were collected from the China Meteorological Data Sharing Service System (http://data.cma.cn/). The ordinary Kriging method embedded in ArcGIS version 10.1 (ESRI Inc., Redlands, California, USA) was used to interpolate meteorological data at 1000-m spatial resolution using the Albers equal-area conic projection. 


\subsection{Methods}

\subsubsection{Linear regression analysis}

To analyze vegetation dynamics, we used a linear regression model to detect changes in trend in each pixel using the ordinary least squares method. The linear relationship between a dependent variable $(y)$ and an independent variable $(x)$ is expressed as follows:

$$
y=\alpha+\beta x+\varepsilon,
$$

where, $y$ is the annual maximum NDVI; $\alpha$ is the intercept; $\beta$ is the slope; $x$ is the monitored year; and $\varepsilon$ is the error term.

The slope can be interpreted as a measure of the increasing or decreasing trend in vegetation productivity over time. Specifically, slope $>0$ indicates an increasing trend of NDVI and thus an increasing vegetation productivity, while slope $<0$ indicates a decreasing NDVI and thus a decreasing vegetation productivity. Tests of significance were based on the two-tail probability, and difference was considered significant at $P<0.05$ level.

\subsubsection{Residual trend (RESTREND) method}

The RESTREND method is used to investigate trends in residual differences between observed NDVI $\left(\mathrm{NDVI}_{\mathrm{obs}}\right)$ and predicted NDVI $\left(\mathrm{NDVI}_{\mathrm{pre}}\right)$ using a regression model involving climate factors as the explanatory variables (Evans and Geerken, 2004; Guo et al., 2012). The climate factors (Peng et al., 2011; Guo et al., 2012) used in this study included the cumulative precipitation from January to August $(P)$, the coefficient of variance for seasonal distribution of precipitation from May to August $(S D P)$ and the accumulated temperature above $0^{\circ} \mathrm{C}$ from January to August $(T)$. The RESTREND method involved the following four steps.

First, an exponential regression model between $\mathrm{NDVI}_{\mathrm{obs}}$ and each climate factor $(P, T$, and $S D P$ ) was used to obtain the regression function (Boer and Puigdefábregas, 2003).

$$
\begin{array}{cc}
N D V I_{o b s}=0.076 \exp (0.0079 P) & \left(R^{2}=0.945, P<0.01\right), \\
N D V I_{o b s}=1295.7 \exp (-0.098 T) & \left(R^{2}=0.863, P<0.01\right), \\
N D V I_{o b s}=0.0286 \exp (6.1458 S D P) & \left(R^{2}=0.935, P<0.01\right) .
\end{array}
$$

Second, $\mathrm{NDVI}_{\text {pre }}$ was calculated as the minimum index value corresponding to each regression value (Sun et al., 2008).

$$
N D V I_{\text {pre }}=\min \left\{f_{1}(P), f_{2}(T), f_{3}(S D P)\right\} .
$$

Third, the residual difference between $\mathrm{NDVI}_{\mathrm{obs}}$ and $\mathrm{NDVI}_{\text {pre }}$ was calculated.

Fourth, the trends of NDVI pre values and RESTREND residuals as a function of time were carried out. Specifically, trends in $\mathrm{NDVI}_{\text {pre }}$ values were interpreted as climate-induced changes, while trends in RESTREND residuals were interpreted as human-induced changes.

Totally, eight scenarios were used to differentiate the relative importance of climate factors and human activities in impacting vegetation dynamics (Table 1) (Xu et al., 2009; Zhou et al., 2015).

Table 1 Eight scenarios for differentiating the relative importance of climate factors and human activities in impacting vegetation dynamics

\begin{tabular}{cccl}
\hline $\begin{array}{l}\text { Slope of } \\
\text { NDVI }_{\text {obs }}\end{array}$ & $\begin{array}{l}\text { Slope of } \\
\text { NDVI }_{\text {pre }}\end{array}$ & $\begin{array}{l}\text { Slope of } \\
\text { residual }\end{array}$ & Definition \\
\hline \multirow{4}{*}{$<0$} & $>0$ & $<0$ & Human-induced vegetation degradation \\
& $<0$ & $>0$ & Climate-induced vegetation degradation \\
& $<0$ & $<0$ & Both climate- and human-induced vegetation degradation \\
& $>0$ & $>0$ & $\begin{array}{l}\text { Error (because both climate factors and human activities contributed to vegetation } \\
\text { recovery, but the vegetation actually displayed degradation) }\end{array}$ \\
& $<0$ & $>0$ & Human-induced vegetation recovery \\
& $>0$ & $<0$ & Climate-induced vegetation recovery \\
& $>0$ & $>0$ & Both climate- and human-induced vegetation recovery \\
& $<0$ & $<0$ & Error (because both climate factors and human activities induced vegetation degradation, \\
but the vegetation actually displayed recovery)
\end{tabular}




\section{Results}

\subsection{Vegetation dynamics and land-cover changes}

The changing trends of NDVI during the period 2000-2015 are shown in Figure 2. There was no significant change trend of NDVI over $84.15 \%$ of the study area during the study period, while significant change trends were observed in $15.85 \%$ of the study area (including positive trends in $14.28 \%$ of the study area and negative trends in $1.57 \%$ of the study area). Generally speaking, areas showing positive trends of NDVI were widespread in the central region, indicating vegetation recovery during this period. And, areas showing negative trends of NDVI were concentrated in the northeastern and northwestern regions, indicating vegetation degradation.

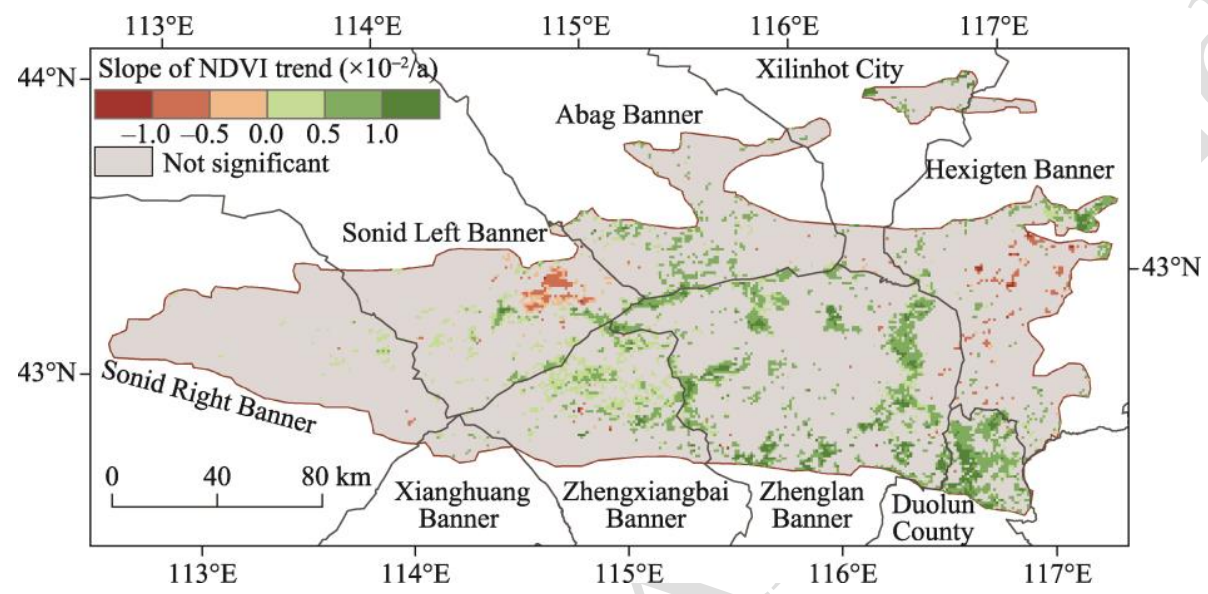

Fig. 2 Linear regression slope values for the trends of NDVI during the period 2000-2015. It should be noted that slope $>0$ indicates positive NDVI trend and vegetation recovery, while slope $<0$ indicates negative NDVI trend and vegetation degradation. The statistical significance was tested using the $t$-statistic $(P<0.05)$.

Grasslands and barren lands (including barren lands and sparsely vegetated lands) were the two major land-cover types in the Otindag Sandy Land. As shown in Figure 3, areas of these two major land-cover types all showed obvious and irregular changes during 2001-2013. The area of other land-cover types (including croplands, shrublands, forests, water bodies, and urban areas) has also changed.

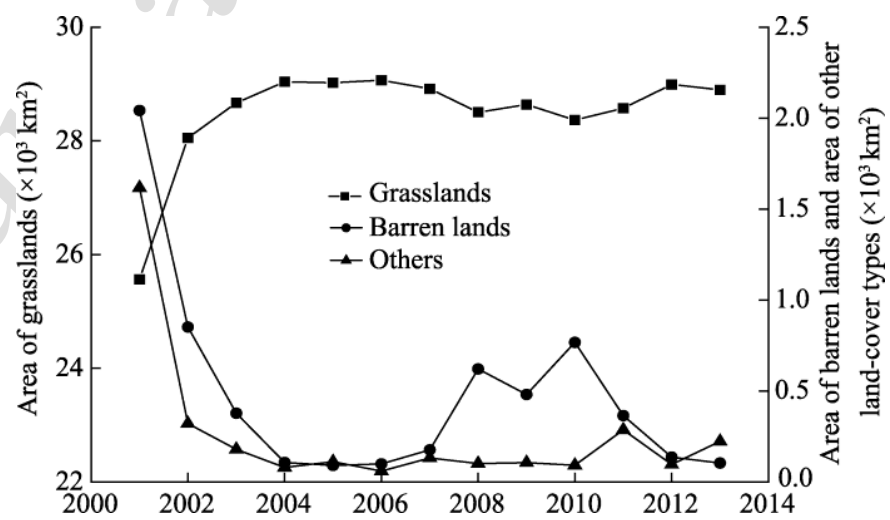

Fig. 3 Areas of grasslands, barren lands (including barren lands and sparsely vegetated lands) and other land-cover types (including croplands, shrublands, forests, water bodies and urban areas) during 2001-2013

\subsection{Relative importance of climate factors and human activities}

The relative importance of climate factors and human activities in impacting vegetation dynamics is shown in Figure 4. Vegetation recovery was resulted from climate factors in the northern region, 
from human activities in the southeastern region, and from both climate factors and human activities in the central and western regions. Vegetation degradation was resulted from human factors in the northwestern and northeastern regions and from both climate factors and human activities in the eastern region. It should be particularly noted that slight errors occurred only in the southeastern region, implying that the results from the RESTREND method are acceptable.

The area with vegetation degradation solely resulted from human activities accounted for $8.23 \%$ of the study area, while the area with vegetation degradation resulted from others (including climate factors and combination of climate factors and human activities) occupied $1.53 \%$ of the study area. The area with vegetation recovery benefitted from human activities (including ecological restoration projects and appropriate cultivation) occurred over $26.02 \%$ of the study area; the area with vegetation recovery benefitted from climate factors accounted for $23.69 \%$; and the area with vegetation recovery benefitted from both climate factors and human activities occupied $37.74 \%$.

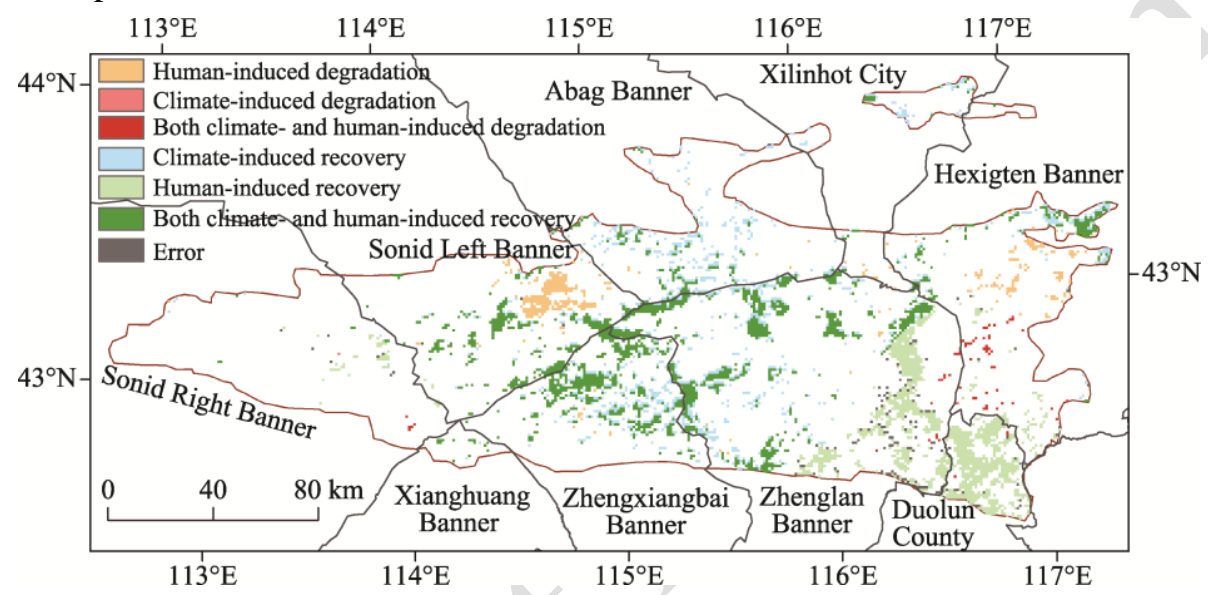

Fig. 4 Relative importance of climate factors and human activities in impacting vegetation dynamics (degradation and recovery) in the Otindag Sandy Land

\section{Discussion}

\subsection{Vegetation dynamics and desertification}

During the period of 2000-2015, vegetation condition in the study area showed an overall positive trend, indicating a reversal of desertification (vegetation recovery). Increased area of grasslands, the return of croplands to grasslands/shrublands, and grassland succession may contribute to the reversal of desertification (Wang et al., 2008; Kang et al., 2009). The detected vegetation degradation has inevitably led to an observable increase in bare soil area and the development of a desert-like landscape in this region (Zhu and Wang, 1992; Wang et al., 2002; Lin et al., 2010).

In fact, accurately assessing vegetation condition in the Otindag Sandy Land has certain difficulty. For example, in the field survey we found that large areas of highly palatable species including L. chinensis and S. grandis were replaced by Stellera chamaejasme, a poisonous and undesirable species (Fig. 5). Although the spread of $S$. chamaejasme led to an increase in vegetation biomass, its proliferation actually resulted in a decrease in carrying capacity and a reduction in the sustainability of livestock systems ( $\mathrm{Lu}$ et al., 2013). When this vegetation condition (spread of $S$. chamaejasme) is considered to be a sign of desertification intensification, its NDVI detection in satellite images is quite misleading because the NDVI suggests a reversal of desertification. Of course, due to limitations in human and material resources, it is impossible to survey the entire area of the Otindag Sandy Land to map out the distribution of spread of all poisonous weeds. In this study, the spread of S. chamaejasme was confirmed and recognized in the southeastern region; however, there may be other similar phenomenon that can also mislead the interpretation of satellite images. Thus, hyperspectral datasets are expected to obtain more 
details (such as the spread of poisonous weeds) to accurately assess vegetation dynamics (Mansour et al., 2012; Götze et al., 2016).

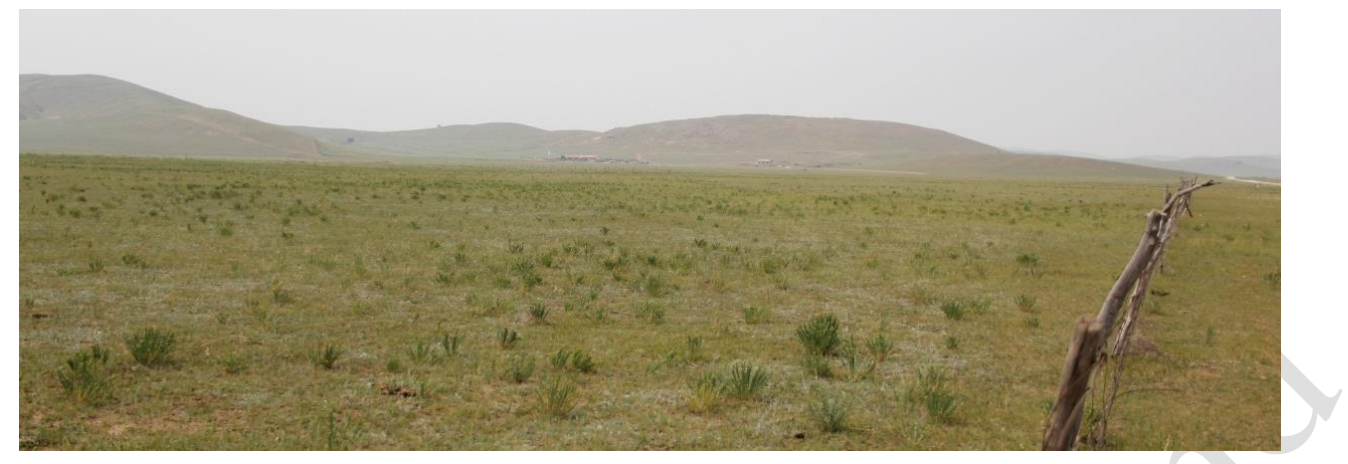

Fig. 5 Stellera chamaejasme in Zhenglan Banner $\left(42.428^{\circ} \mathrm{N}, 116.087^{\circ} \mathrm{E}\right)$ in July 2016

\subsection{Relative importance of climate factors and human activities}

Climate affects vegetation dynamics mainly through changes in precipitation and temperature (Chuai et al., 2013) and precipitation is more important than temperature in impacting vegetation dynamics in arid and semi-arid areas (Sun et al., 2010; Xu et al., 2010; Chuai et al., 2013). It was reported that the precipitation seasonality is even more important than the precipitation amount in affecting vegetation dynamics in the Otindag Sandy Land (Guo et al., 2012). Human activities exert the impacts on vegetation dynamics mainly through socioeconomic development and related activities (Dong et al., 2015). In the Otindag Sandy Land, there has been large- and small-scale strip mining activities in grazing lands and the mining activities have been tightly associated with constructions of roads and supporting facilities and buildings. Strip mining has been recognized as one of the major factors affecting grassland productivity in this region (Dong et al., 2015). On the other hand, the implementation of effective ecological restoration projects has contributed to vegetation recovery in the fragile western region, while reduced grazing intensity and land reclamation have contributed to vegetation recovery in the southern region (Zhang et al., 2005; Dong et al., 2011).

Throughout the entire Otindag Sandy Land, climate factors and human activities played more or less equally important roles in vegetation recovery. However, human activities were identified as the main driving forces in vegetation degradation. As shown in Figure 6, the total sown area and total livestock number showed different trends at the county/city/banner scales between 2000 and 2015. The trends were similar in Xilinhot City and Hexigten Banner, where vegetation degradation may result from inappropriate cultivation activities. There was a return of croplands to grasslands in Duolun County, Zhengxiangbai Banner and Xianghuang Banner. It should be particularly noted that Duolun County, a typical agriculture-pasture transition zone, exhibited the largest land-use transformation and the largest positive trend in NDVI. Vegetation recovery in Zhenglan Banner and Abag Banner was primarily benefited from increased precipitation and decreased livestock grazing intensity. Due to increased industrial activities, NDVI in Sonid Left Banner showed a negative trend. These results indicate that relative importance of climate factors and human activities in impacting vegetation dynamics varied at the county/city/banner scales and locality-specific measures should be adopted to protect the environments.

To further validate our results, we used medium-resolution datasets including TM images and OLI images derived from the Landsat satellite. The regions subjected to significant vegetation changes were detected by comparing Landsat TM images in 2000 and Landsat OLI images in 2014 through visual interpretation. From Figure 7 we infer that excessive cultivation practices in the northeastern region of the Otindag Sandy Land (Fig. 7a) and land reclamation in desert areas (Fig. 7b) led to vegetation degradation in the eastern region. Increases in areas of grasslands and shrublands (Fig. 7c) and decreases in areas of sand dunes and bare lands (Fig. 7e) were resulted from both human activities and combination of climate factors and human activities in the central 
and southwestern regions. In addition, the conversion of croplands to grasslands in the southern region (Fig. 7d) and the expansion of wheel-rutted desert roads in the western bare sand dunes (Fig. 7f) were caused by human activities.

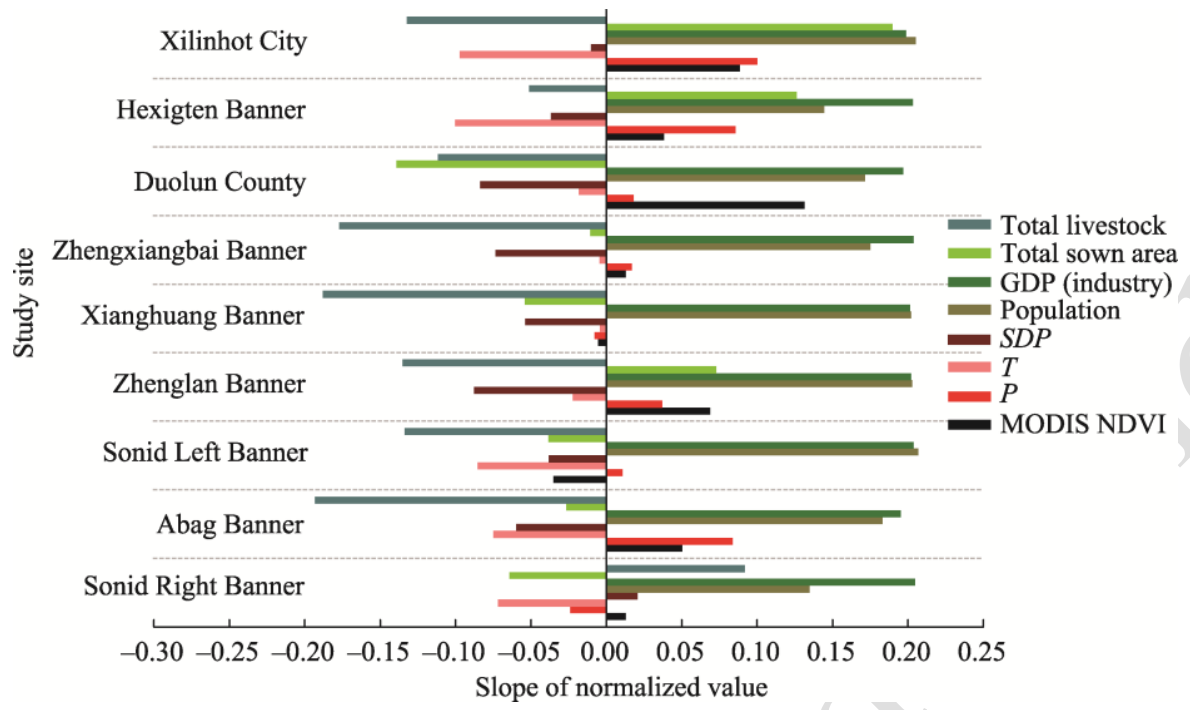

Fig. 6 Slopes (or trends) of normalized value for human factors (including total livestock, total sown area, GDP (industry) and population), climate factors (including SDP, $T$ and $P$ ) and MODIS NDVI in each of counties/cities/banners during 2000-2015. SDP, coefficient of variance for seasonal distribution of precipitation from May to August; $T$, accumulated temperature above $0^{\circ} \mathrm{C}$ from January to August; $P$, cumulative precipitation from January to August.

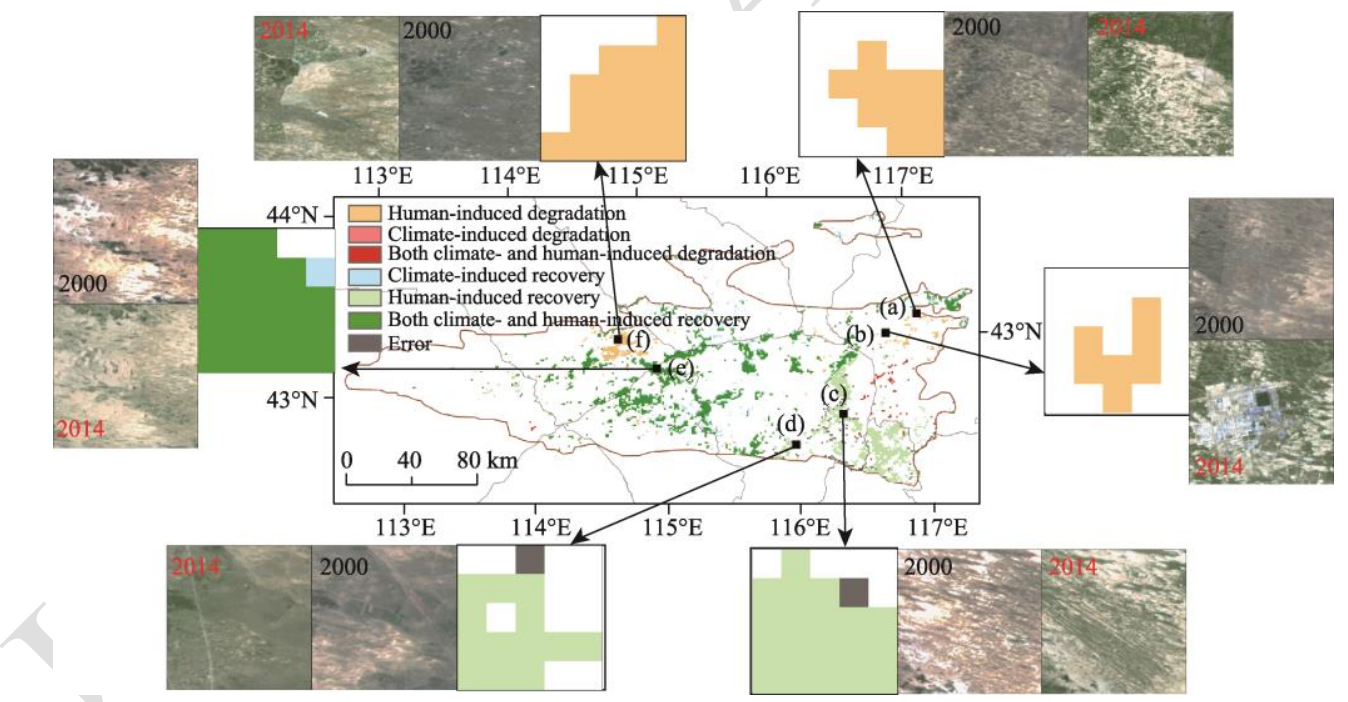

Fig. 7 Representative examples of vegetation conditions in 2000 and 2014 in the Otindag Sandy Land. Each example includes a Landsat TM image in July 2000 and a Landsat OLI image in July 2014. (a), bare lands resulted from excessive cultivation practices; (b), land reclamation in desert areas; (c), increases in areas of grasslands and shrubs; (d), conversion of croplands to grasslands; (e) decreases in areas of sand dunes and bare lands; (f), expansion of wheel-rutted desert roads. It should be noted that the central figure is the same as Figure 4.

\section{Conclusions}

Based on time series of MODIS NDVI records during 2000-2015 and linear regression analysis, we found that both vegetation recovery (positive trend in NDVI) and vegetation degradation (negative trend in NDVI) existed in the Otindag Sandy Land. Overall, vegetation condition in the 
study area showed a positive trend during the study period, indicating a reversal of desertification (i.e., vegetation recovery). In addition, most areas of barren lands were converted to grasslands. Results from the RESTREND method showed that climate factors generally had favorable impacts on vegetation recovery over most of the study area, while human activities exhibited variable impacts on vegetation dynamics at the county/city/banner scales. Reasonable land reclamation and appropriate livestock grazing intensity may have contributed to the vegetation recovery in the western and southern regions. In contrast, inappropriate cultivation, mining exploitation, and road expansion may have resulted in vegetation degradation in the northeastern and northwestern regions.

\section{Acknowledgements}

This study was supported by the National Key Research and Development Program of China (2016YFA0601900) and the National Natural Science Foundation of China (41401006).

\section{References}

Boer M M, Puigdefábregas J. 2003. Predicting potential vegetation index values as a reference for the assessment and monitoring of dryland condition. International Journal of Remote Sensing, 24(5): 1135-1141.

Chuai X W, Huang X J, Wang W J, et al. 2013. NDVI, temperature and precipitation changes and their relationships with different vegetation types during 1998-2007 in Inner Mongolia, China. International Journal of Climatology, 33(7): 1696-1706.

Dong J W, Liu J Y, Yan H M, et al. 2011. Spatio-temporal pattern and rationality of land reclamation and cropland abandonment in mid-eastern Inner Mongolia of China in 1990-2005. Environmental Monitoring and Assessment, 179(1-4): $137-153$.

Dong X B, Dai G S, Ulgiati S, et al. 2015. On the relationship between economic development, environmental integrity and well-being: the point of view of herdsmen in northern China grassland. PLoS ONE, 10(9): e0134786, doi: 10.1371/journal.pone.0134786.

Eckert S, Hüsler F, Liniger H, et al. 2015. Trend analysis of MODIS NDVI time series for detecting land degradation and regeneration in Mongolia. Journal of Arid Environments, 113: 16-28.

Evans J, Geerken R. 2004. Discrimination between climate and human-induced dryland degradation. Journal of Arid Environments, 57(4): 535-554.

Fensholt R, Rasmussen K. 2011. Analysis of trends in the Sahelian 'rain-use efficiency' using GIMMS NDVI, RFE and GPCP rainfall data. Remote Sensing of Environment, 115(2): 438-451.

Götze C, Beyer F, Gläßer C. 2016. Pioneer vegetation as an indicator of the geochemical parameters in abandoned mine sites using hyperspectral airborne data. Environmental Earth Sciences, 75(7): 613. doi: 10.1007/s12665-016-5367-1.

Guo Q, Hu Z M, Li S G, et al. 2012. Spatial variations in aboveground net primary productivity along a climate gradient in Eurasian temperate grassland: effects of mean annual precipitation and its seasonal distribution. Global Change Biology, 18(12): 3624-3631.

He C Y, Tian J, Gao B, et al. 2015. Differentiating climate- and human-induced drivers of grassland degradation in the Liao River Basin, China. Environmental Monitoring and Assessment, 187(1): 4199, doi: 10.1007/s10661-014-4199-2.

Kang X W, Wu S H, Liu X H. 2009. Research on spatio-temporal change of sandy desertification in Hunshandake. Journal of Soil and Water Conservation, 23(1): 1-6. (in Chinese)

Li A, Wu J G, Huang J H. 2012. Distinguishing between human-induced and climate-driven vegetation changes: a critical application of RESTREND in Inner Mongolia. Landscape Ecology, 27(7): 969-982.

Lin Y, Han G D, Zhao M L, et al. 2010. Spatial vegetation patterns as early signs of desertification: a case study of a desert steppe in Inner Mongolia, China. Landscape Ecology, 25(10): 1519-1527.

Liu H J, Zhou C H, Cheng W M, et al. 2008. Monitoring sandy desertification of Otindag Sandy Land based on multi-date remote sensing images. Acta Ecologica Sinica, 28(2): 627-635.

Liu S L, Wang T. 2007. Aeolian desertification from the mid-1970s to 2005 in Otindag Sandy Land, Northern China. Environmental Geology, 51(6): 1057-1064.

Liu X F, Zhu X F, Pan Y Z, et al. 2016. Vegetation dynamics in Qinling-Daba Mountains in relation to climate factors between 2000 and 2014. Journal of Geographical Sciences 26(1): 45-58.

Lu H, Wang S S, Zhou Q W, et al. 2013. Damage and control of major poisonous plants in the western grasslands of China-a 
review. The Rangeland Journal, 34(4): 329-339.

Mansour K, Mutanga O, Everson T, et al. 2012. Discriminating indicator grass species for rangeland degradation assessment using hyperspectral data resampled to AISA Eagle resolution. ISPRS Journal of Photogrammetry and Remote Sensing, 70: $56-65$.

Miao L J, Moore J C, Zeng F J, et al. 2015. Footprint of research in desertification management in China. Land Degradation \& Development, 26(5): 450-457.

Mirzabaev A, Ahmed M, Werner J, et al. 2016. Rangelands of Central Asia: challenges and opportunities. Journal of Arid Land, 8(1): 93-108.

Peng S S, Chen A P, Xu L, et al. 2011. Recent change of vegetation growth trend in China. Environmental Research Letters, 6(4): 044027, doi: 10.1088/1748-9326/6/4/044027.

Qin D H. 2014. Climate change science and sustainable development. Progress in Geography, 33(7): 874-883. (in Chinese)

Seaquist J W, Hickler T, Eklundh L, et al. 2008. Disentangling the effects of climate and people on Sahel vegetation dynamics. Biogeosciences Discussions, 5(4): 3045-3067.

Sun J G, Ai T H, Wang P, et al. 2008. Assessing vegetation degradation based on NDVI-climate variables feature space. Geomatics and Information Science of Wuhan University, 33(6): 573-576. (in Chinese)

Sun Y L, Guo P, Yan X D, et al. 2010. Dynamics of vegetation cover and its relationship with climate change and human activities in Inner Mongolia. Journal of Natural Resources, 25(3): 407-414. (in Chinese)

Wang F, Pan X B, Wang D F, et al. 2013. Combating desertification in China: past, present and future. Land Use Policy, 31 : 311-313.

Wang T, Zhu Z D, Wu W. 2002. Sandy desertification in the North of China. Science in China, 45(Suppl.): 23-34.

Wang T, Sun J G, Han H, et al. 2012. The relative role of climate change and human activities in the desertification process in Yulin region of northwest China. Environmental Monitoring and Assessment, 184(12): 7165-7173.

Wang X M, Chen F H, Dong Z B. 2006. The relative role of climatic and human factors in desertification in semiarid China. Global Environmental Change, 16(1): 48-57.

Wang X M, Chen F H, Hasi E, et al. 2008. Desertification in China: an assessment. Earth-Science Reviews, 88(3-4): 188-206. Wessels K J, Prince S D, Malherbe J, et al. 2007. Can human-induced land degradation be distinguished from the effects of rainfall variability? A case study in South Africa. Journal of Arid Environments, 68(2): 271-297.

Xu D Y, Kang X W, Liu Z L, et al. 2009. Assessing the relative role of climate change and human activities in sandy desertification of Ordos region, China. Science in China Series D: Earth Sciences, 52(6): 855-868.

Xu D Y, Li C L, Zhuang D F, et al. 2011. Assessment of the relative role of climate change and human activities in desertification: a review. Journal of Geographical Sciences, 21(5): 926-936.

Xu X, Li X B, Liang H W, et al. 2010. Change in vegetation coverage and its relationships with climatic factors in temperate steppe, Inner Mongolia. Acta Ecologica Sinica, 30(14): 3733-3743. (in Chinese)

Xue Z J, Qin Z D, Li H J, et al. 2013. Evaluation of aeolian desertification from 1975 to 2010 and its causes in northwest Shanxi Province, China. Global and Planetary Change, 107: 102-108.

Yang X, Zhang K, Jia B, et al. 2005. Desertification assessment in China: an overview. Journal of Arid Environments, 63(2): 517-531.

Yang X, Ding Z, Fan X, et al. 2007. Processes and mechanisms of desertification in northern China during the last 30 years, with a special reference to the Hunshandake Sandy Land, eastern Inner Mongolia. CATENA, 71(1): 2-12.

Zhang J Y, Wang Y, Zhao X, et al. 2005. Grassland recovery by protection from grazing in a semi-arid sandy region of northern China. New Zealand Journal of Agricultural Research, 48(2): 277-284.

Zhang Y Z, Chen Z Y, Zhu B Q, et al. 2008. Land desertification monitoring and assessment in Yulin of Northwest China using remote sensing and geographic information systems (GIS). Environmental Monitoring and Assessment, 147(1-3): $327-337$.

Zheng Y R, Xie Z X, Robert C, et al. 2006. Did climate drive ecosystem change and induce desertification in Otindag sandy land, China over the past 40 years? Journal of Arid Environments, 64(3): 523-541.

Zhou W, Gang C C, Zhou F C, et al. 2015. Quantitative assessment of the individual contribution of climate and human factors to desertification in northwest China using net primary productivity as an indicator. Ecological Indicators, 48: 560-569.

Zhu Z D. 1991. Fragile ecological zones and land desertification in China. Journal of Desert Research, 11(4): 11-22. (in Chinese)

Zhu Z D, Wang T. 1992. Theory and practice on sandy desertification in China. Quaternary Sciences, 12(2): 97-106. (in Chinese) 